\title{
Effect of sulphasalazine and its active metabolite, 5-amino-salicylic acid, on toxic oxygen metabolite production by neutrophils
}

\author{
J G WILliaMS AND M B HALLETT \\ From the Department of Surgery, University of Wales College of Medicine, Cardiff
}

SUMmary The possibility that the mode of action of sulphasalazine and its active metabolite 5-amino-salicylic acid (5ASA) involves modification of toxic oxygen metabolite production by neutrophils has been investigated by measuring the effect of these drugs on luminol-dependent chemiluminescence, superoxide release and oxygen consumption by stimulated neutrophils in vitro. 5ASA, and to a lesser extent sulphasalazine, had profound inhibitory effects on the luminol dependent chemiluminescent response of neutrophils stimulated with formyl-methionyl-leucylphenylalanine $(1 \mu \mathrm{M})+$ cytochalasin B $(5 \mu \mathrm{g} / \mathrm{ml})$. A concentration of $50 \mu \mathrm{M} 5 \mathrm{ASA}$ or sulphasalazine produced $93.8(2 \cdot 3) \%$ and $65.7(3 \cdot 7) \%$ inhibition of control responses respectively. The concentration of 5ASA and sulphasalazine producing $50 \%$ inhibition of chemiluminescence were $3 \cdot 6(1 \cdot 8) \mu \mathrm{M}$ and 16.5 (6) $\mu \mathrm{M}$ respectively. Both drugs had little effect on the chemiluminescent response of neutrophils stimulated with phorbol myristate acetate $(1 \mu \mathrm{g} / \mathrm{ml})$, producing only $11 \cdot 4(3.9) \%$ and 34 (7)\% inhibition respectively, at a concentration of $50 \mu \mathrm{M}$. Superoxide release from fMLP+CB stimulated neutrophils was also inhibited slightly by $5 \mathrm{ASA}(50 \mu \mathrm{M})$ by $35 \cdot 6 \%$ and by sulphasalazine $(50 \mu \mathrm{M})$ by $7 \cdot 9 \%$. Similarly, there was little inhibition in the rate of oxygen consumption by fMLP+ CB stimulated neutrophils by either 5ASA or sulphasalazine at concentrations which produced near total abolition of luminol dependent chemiluminescence. These results show that sulphasalazine and 5ASA inhibit the reaction of toxic metabolites produced by stimulated neutrophils with luminol, without inhibition of the oxidase system producing these metabolites. The site of action of these drugs on neutrophils in vitro is thus extracellular, by scavenging a released metabolite, probably hypochlorite. This has important implications for their mode of action in vivo in inflammatory bowel disease.

The beneficial effects of sulphasalazine on ulcerative colitis were first noted in the 1940 s.' Sulphasalazine is broken down in the colon by enteric bacteria into sulphapyridine and 5-amino-salicylic acid (5ASA). ${ }^{2.3}$ The active metabolite of SAL is $5 \mathrm{ASA}^{45}$ which has recently been used in the treatment of ulcerative colitis, being delivered to the colon in a $\mathrm{pH}$ sensitive coated capsule."

The mode of action of sulphasalazine and its active metabolite, 5ASA, in inflammatory bowel disease

Address for correspondence: Mr J G Williams, FRCS, Department of Surgery. University of Wales College of Medicine Heath Park, Cardiff CF4 4XN.

Accepted for publication 8 March 1989. remains uncertain. Both ulcerative colitis and Crohn's disease are characterised by infiltration of the mucosa with neutrophils and macrophages. These cells produce highly reactive metabolites of oxygen including superoxide $\left(\mathrm{O}_{2}^{-}\right)$, hydrogen peroxide $\left(\mathrm{H}_{2} \mathrm{O}_{2}\right)$ and the hydroxyl radical $(\mathrm{OH}){ }^{84}$ Further reactions with myeloperoxidase, released simultaneously, results in the formation of hypochlorite $\left(\mathrm{OCl}^{-}\right) .{ }^{\prime \prime}$ Extracellular release of these phagocyte generated metabolites of oxygen is thought to play a major role in the pathogenesis of tissue damage at inflammatory sites. ${ }^{11}$ In inflammatory bowel disease, phagocytic cells retain the ability to produce toxic oxygen metabolites,,${ }^{12}$ further- 
more, in inflamed tissue, these cells produce an enhanced response to stimulation. ${ }^{13}$

A drug which reduces reactive oxygen metabolite production by phagocytic cells, either by a direct inhibitory effect on the cells, or by scavenging released oxygen metabolites, may therefore reduce tissue damage at inflammatory sites.

In this paper, we investigate the possibility that sulphasalazine and 5ASA modify reactive oxygen metabolite production by neutrophils in vitro. By monitoring different aspects of oxygen metabolite production by stimulated neutrophils, we show that these drugs act at a specific extracellular site.

\section{Methods}

ISOLATION OF NEUTROPHILS

Neutrophils were isolated from freshly drawn whole blood from healthy volunteers, by dextran sedimentation $^{14}$ and density gradient centrifugation over Ficoll-Paque (Pharmacia, Sweden). ${ }^{15}$ Neutrophils were washed twice in HEPES ( $\mathrm{N}$-2-hydroxyethyl piperazine-N-2-ethane sulphonic acid) buffered Krebs solution ( $120 \mathrm{mM} \mathrm{NaC1}, 4.8 \mathrm{mM} \mathrm{KC} 1,1.2 \mathrm{mM}$ $\mathrm{MgSO}_{4}, 1.2 \mathrm{mM} \mathrm{KH} \mathrm{PO}_{4}, 1.3 \mathrm{mM} \mathrm{CaCl} 2,0.1 \%$ bovine serum albumin and $25 \mathrm{mM}$ HEPES, $\mathrm{pH}$ was adjusted to $7 \cdot 4$ with $\mathrm{NaOH}$ ). After washing, neutrophils were suspended in fresh Krebs solution (between 1 and $5 \times 10^{\circ}$ cells $/ \mathrm{ml}$ ) on melting ice until required. Neutrophil suspensions were $>95 \%$ pure and $>95 \%$ viable (assessed by exclusion of trypan blue).

MEASUREMIENT OF TOXIC OXYGEN MIETABOIITE PRODUCTION

\section{Chemiluminescence}

Luminol dependent chemiluminescence ${ }^{16}$ was measured with a photomultiplier tube (Thorn EMI $30 \mathrm{~mm}$ bialkaline front surface, no 9924B. High voltage supply $940 \mathrm{~V}$, discriminator set at $(0 \cdot 1 \mathrm{~V}$ ) in a specially constructed light tight chamber, thermostatically controlled at $37^{\circ} \mathrm{C} .1^{17}$ One millilitre of neutrophil suspension was placed in a plastic test tube, to which was added luminol dissolved in dimethyl sulphoxide (DMSO), final concentration luminol $11 \mu \mathrm{M}, 0 \cdot 1 \% \mathrm{v} / \mathrm{v}$ DMSO. Sulphasalazine and 5ASA were dissolved in DMSO and added to the cell suspensions before addition of the stimulus (final concentration of drugs ranged from $0 \cdot 1 \mu \mathrm{M}$ to 100 $\mu \mathrm{M})$. A similar volume of DMSO $(1.5 \mu \mathrm{l})$ was added to control samples.

Neutrophils were stimulated with either chemotactic peptide $\mathrm{N}$ formyl-methionyl-leucyl-phenylalanine ( $\mathrm{fMLP}$, final concentration $1 \mu \mathrm{M}$ ) plus cytochalasin $\mathrm{B}(\mathrm{CB}$, final concentration $5 \mu \mathrm{g} / \mathrm{ml})$ or the
C kinase activator $4 \beta$ phorbol 12 myristate 13 acetate PMA (final concentration $1 \mu \mathrm{g} / \mathrm{ml}$ ). The luminol dependent chemiluminescent response in photon counts per second was recorded with a pen chart recorder.

SUPEROXIDE PRODUCTION

Superoxide production by stimulated neutrophils was measured by reduction of cytochrome C. ${ }^{\text {" }}$ One millilitre aliquots of neutrophil suspension $\left(1 \times 10^{\circ}\right.$ neutrophils) were placed in plastic cuvettes $(1 \mathrm{~cm}$ light path), to which was added cytochrome $\mathrm{C}$ type III (Sigma Chemical Co., Poole, Dorset) to a final concentration of $50 \mu \mathrm{M}$. Sulphasalazine or 5ASA, dissolved in DMSO, were added to the neutrophils (final concentration of sulphasalazine and 5ASA, $50 \mu \mathrm{M}$; DMSO $0 \cdot 15 \% \mathrm{v} / \mathrm{v}$ ). Cells were stimulated with fMLP $(1 \mu \mathrm{M})$ plus CB $(5 \mu \mathrm{g} / \mathrm{ml})$.

Reduction of cytochrome $\mathrm{C}$ was measured by absorbance at $550 \mathrm{~nm}$ in a PYE SP30 UV spectrophotometer, against a blank cuvette containing a similar volume of neutrophil suspension, and similar concentrations of cytochrome C, fMLP+CB and 300) units superoxide dismutase (Sigma Chemical Co.). Superoxide production was calculated from the rate of change of absorbance using Beer-Lamberts law, with the extinction coefficient $E_{550}=2 \cdot 1 \times 10^{+} / \mathrm{M} / \mathrm{cm}$. Each experiment was performed in triplicate using neutrophils from five different subjects.

OXYGEN CONSUMPTION

Oxygen consumption was measured using a Clark clectrode in a purpose built chamber, maintained at $37^{\circ} \mathrm{C} .{ }^{19}$ The polarising voltage of the electrode was maintained at $0.6 \mathrm{~V}$ and the output of the electrode was measured with a purpose built nano-ammeter and a chart recorder. The apparatus was calibrated by assuming that the concentration of oxygen dissolved in HEPES buffered Krebs medium at $37^{\circ} \mathrm{C}$ was $210 \mu \mathrm{M} .{ }^{21} 1.5 \times 10^{7}$ neutrophils, suspended in $2 \mathrm{ml}$ HEPES buffered Krebs medium, were placed in the specimen chamber, and allowed to reach steady state resting oxygen consumption.

Neutrophils were stimulated by adding FMLP (final concentration, $1 \mu \mathrm{M}$ ) and $\mathrm{CB}$ (final concentration $5 \mu \mathrm{g} / \mathrm{ml}$ ). Experiments were performed in triplicate on neutrophils from five different subjects.

\section{Results}

INHIBITION OF LUUMINOI, DEPENDENT

CHEMIIUMINESCENCE

Both sulphasalazine and 5ASA inhibited the burst of chemiluminescence produced by neutrophils when stimulated by $\mathrm{fMLP}+\mathrm{CB}$. This inhibition was characterised by a decrease in peak chemilumines- 


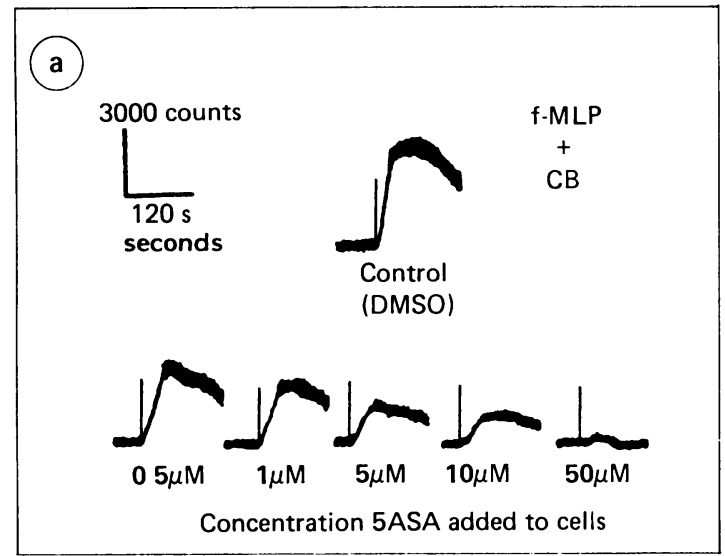

(b)

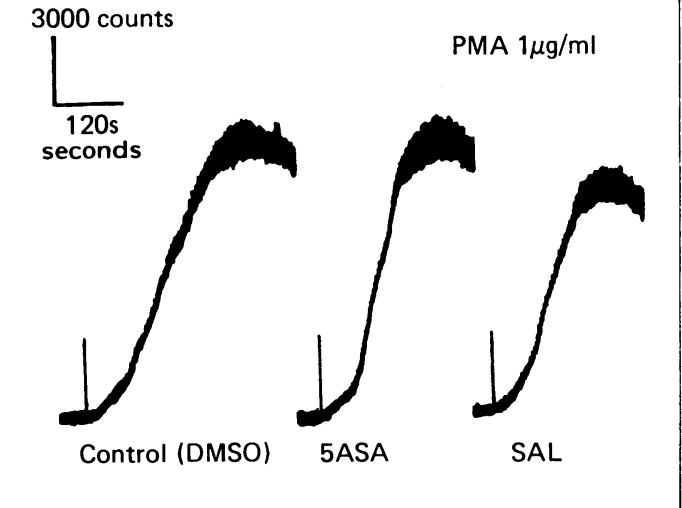

Fig. 1 Luminol dependent chemiluminesence. Pen-chart recordings, showing; (a) the effect of increasing concentrations of $5 \mathrm{ASA}$ on the luminol-dependent chemiluminescent response of neutrophils stimulated with $f M L P(I \mu M)$ and $C B(5 \mu \mathrm{g} / \mathrm{ml})$, and (b) the luminol-dependent chemiluminesent response of neutrophils stimulated with PMA $(1 \mu \mathrm{g} / \mathrm{lml})$, comparing the response of control cells with those cells pretreated with $50 \mu \mathrm{M}$ sulphasalazine or 50 $\mu M 5$ ASA. Neutrophils from the same subject, $2 \times 10^{\prime \prime}$ cells. Stimuls added at vertical mark. Drugs dissolved in DMSO, control samples contained a similar volume of DMSO $(1.5$ $\mu l)$.

cence, without a decrease in the rate of rise, or increase in the lag time between stimulation and onset of response (Fig. 1a). 5ASA was the more potent, $50 \mu \mathrm{M}$ producing $93.8(2.3) \%$ inhibition of the control chemiluminescent response (mean (SE), $\mathrm{n}=12, \mathrm{p}=0.01$ Wilcoxon's rank-sum test on paired data), whereas sulphasalazine at a similar concentration, produced $65 \cdot 7(3 \cdot 7) \%$ inhibition $(n=9, p=0 \cdot 01$ Wilcoxon's rank-sum test). The concentration of sulphasalazine producing $50 \%$ inhibition $\left(\mathrm{Ki}_{50}\right)$ of

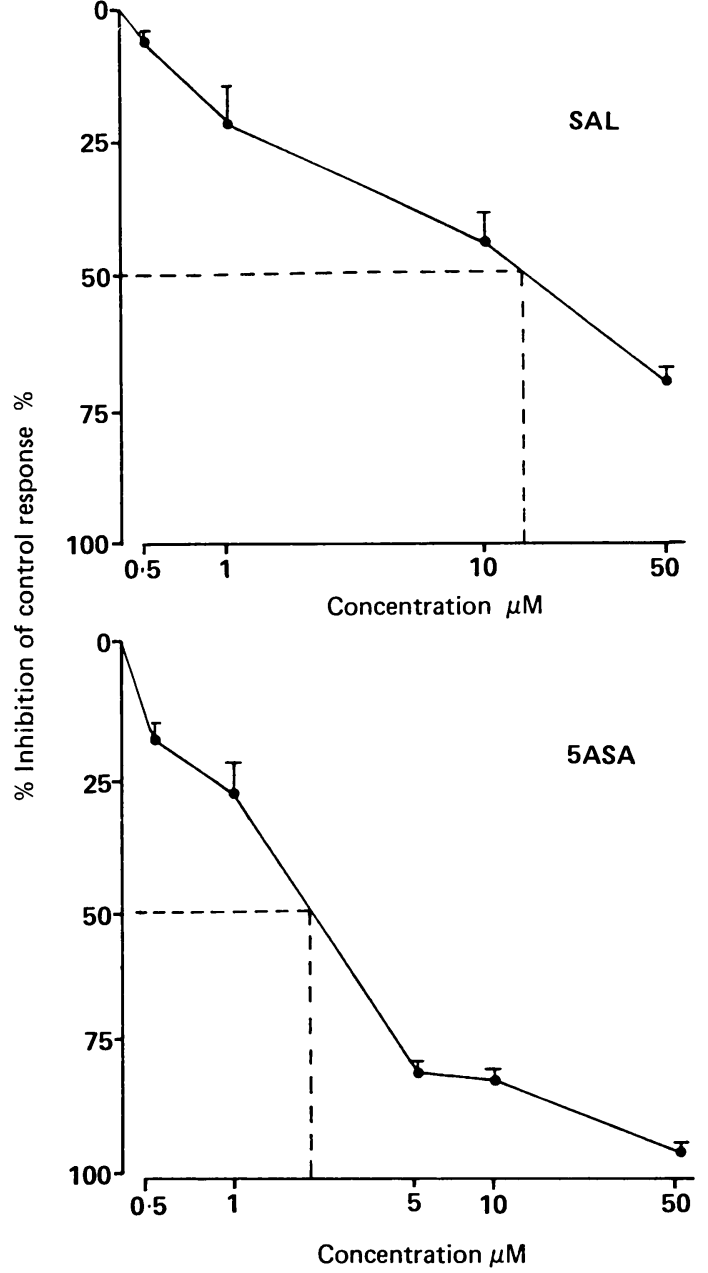

Fig. 2 Luminol dependent chemiluminesence. Graphs showing the inhibitory effect of increasing concentrations of sulphasalazine (SAL) and 5-amino-salicylic acid (5ASA) expressed as percentage inhibition of control values. Each point represents the mean (SD) of observations performed in triplicate on neutrophils from six subjects for 5 ASA and five for $S A L$. Dotted lines mark the concentration producing $50 \%$ inhibition $\left(K i_{50}\right)$. 5ASA-3.6 $\mu \mathrm{M}, S A L$ I6.5 $\mu \mathrm{M}$.

the chemiluminescent response of neutrophils, stimulated with $\mathrm{fMLP}+\mathrm{CB}$ was $16 \cdot 5(6) \mu \mathrm{M}$ (mean (SE) $n=5$, Fig. 2). The $\mathrm{Ki}_{50}$ for 5 ASA was $3.6(1 \cdot 8)$ $\mu \mathrm{M}(\mathrm{n}=6$, Fig. 2). Neutrophils stimulated with fMLP alone produced smaller chemiluminescent responses than in the presence of $\mathrm{CB}$. This smaller chemiluminescent response, however, was also markedly inhibited by $50 \mu \mathrm{M} 5 \mathrm{ASA}(88 \%, \mathrm{n}=3)$ or $50 \mu \mathrm{M} \mathrm{SAL}$ $(81 \cdot 7 \%, n=3)$.

In contrast with the marked inhibition of fMLP+ CB stimulated chemiluminescence by sulphasalazine 
and 5ASA, these drugs in similar concentrations only weakly inhibited chemiluminesence by neutrophils stimulated with PMA (Fig. 1b). Fifty micromolar sulphasalazine produced 34 (7)\% inhibition of control responses (mean (SE), $n=6, p=0 \cdot 0)$ Wilcoxon's rank-sum on paired data). 5ASA, at a similar concentration did not have a significant inhibitory effect $(11.4(3.9) \%, n=10)$.

\section{EFFECT ON SUPEROXIDE PRODUCTION BY}

NEUTROPHILS

At a concentration producing abolition of the chemiluminesent response $(50 \mu \mathrm{M}), 5 \mathrm{ASA}$ produced only $35.6 \%$ inhibition of the rate of production of superoxide $\left(1 \cdot 65(0 \cdot 39) \mathrm{nmoles} / \mathrm{min} / 10^{\mathrm{h}}\right.$ cells, $\mathrm{p}=\mathbf{0} \cdot(\mathbf{0 5}$ Wilcoxon's rank-sum test). Sulphasalazine did not significantly inhibit superoxide production by stimulated neutrophils $\left(2 \cdot 36(0 \cdot 19) \mathrm{nmol} / \mathrm{min} / 10^{\circ}\right.$ neutrophils, $7 \cdot 9 \%$; Table).

\section{EFFECT ON OXYGEN CONSUMPTION BY}

NEUTROPHILS

5-amino-salicylic acid had no significant inhibitory effect on the rate of oxygen consumption by neutrophils stimulated with fMLP $+\mathrm{CB}$ (Fig. 3). The uninhibited stimulated rate was $0.0381(0.025)$ $\mathrm{nmol} / \mathrm{sec} / 10^{\circ}$ neutrophils, and in cells pretreated with 5ASA the rate was $0.0349(0 \cdot 02) \mathrm{nmol} / \mathrm{sec} / 10^{h}$ neutrophils (mean (SD), mean inhibition $8.4 \%$ ).

Sulphasalazine also failed to significantly inhibit oxygen consumption by stimulated neutrophils (Fig. 3). The uninhibited and SAL pre-treated cells consuming oxygen at $0.0363(0.022) \mathrm{nmol} / \mathrm{sec} / 10^{\circ}$ neutrophils, and $0.032(0.021) \mathrm{nmol} / \mathrm{sec} / 10^{\mathrm{h}}$ neutrophils (mean inhibition $11.9 \%$ ) respectively.

\section{Discussion}

In this paper, we have shown that sulphasalazine and its active metabolite 5ASA, have a profound

Table 1 Superoxide production by neutrophils

\begin{tabular}{|c|c|c|}
\hline Control & $50 \mu M 5 A S A$ & $50 \mu M S A L$ \\
\hline $12.42(0.33)$ & $1.45(0.28)[39.9]$ & $2.59(0 \cdot 09)[+7 \cdot 2]$ \\
\hline $22.25(0.51)$ & $1.99(0.59)[11.8]$ & $2 \cdot 48(0 \cdot 48)[+10 \cdot 2]$ \\
\hline $32.66(0 \cdot 08)$ & $1.34(0.28)[49.5]$ & $2 \cdot 11(0 \cdot 31)[20 \cdot 4]$ \\
\hline $42.67(0.25)$ & $2 \cdot 15(0 \cdot 26)[19 \cdot 4]$ & $2 \cdot 41(0 \cdot 36)[9 \cdot 7]$ \\
\hline $52.79(0.48)$ & $1.33(0.35)[52 \cdot 5]$ & $2.21(0.21)[20 \cdot 9]$ \\
\hline \multicolumn{3}{|l|}{ Mean } \\
\hline $2 \cdot 56(0 \cdot 22)$ & $1 \cdot 6.5(0 \cdot 39)[35 \cdot 6]$ & $2 \cdot 36(0 \cdot 19)[7 \cdot 9]$ \\
\hline
\end{tabular}

Effect of $50 \mu \mathrm{M}$ 5ASA and $50 \mu \mathrm{M}$ SAL on superoxide $\left(\mathrm{O}_{2}\right)$ production $\left(\mathrm{nmol} / \mathrm{min} / 10^{n}\right.$ neutrophils) by neutrophils from five healthy subjects, stimulated with fMLP $(1 \mu \mathrm{M})$ and CB $(5 \mu \mathrm{g} / \mathrm{ml})$. Each value is the mean of triplicate measurements (SD). Figures in square parenthesis indicate the $\%$ inhibition of control values. +ve values $=$ enhancement of response.

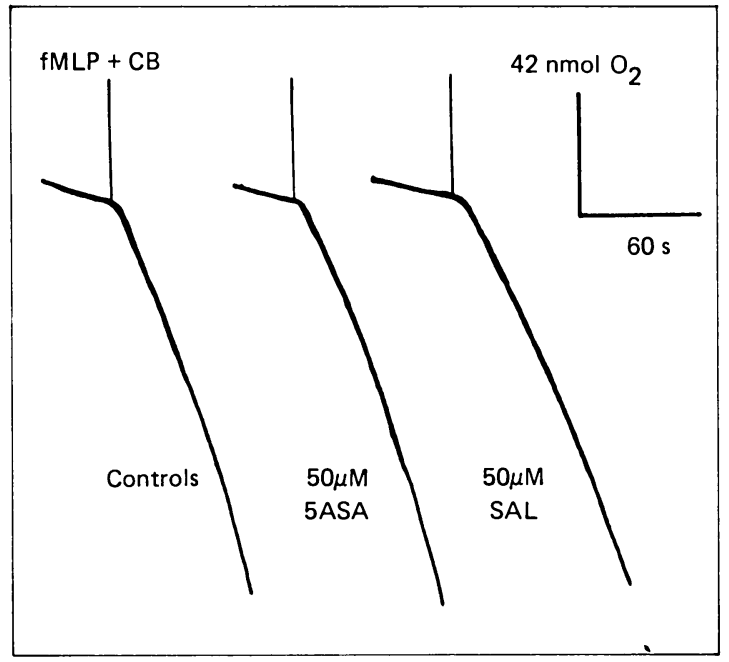

Fig. 3 Oxygen consumption by stimulated neutrophils. Typical pen chart-recording tracings of oxygen consumption by neutrophils measured with a Clark electrode. $1.5 \times 10$ neutrophils in the chamber. Traces show resting oxygen consumption and 'respiratory burst' produced by adding $f M L P(I \mu M)$ and $C B(5 \mu \mathrm{g} / \mathrm{ml})$ at vertical bar on trace. Control rate of oxygen consumption 0.036 nmoles $/ \mathrm{sec}^{\prime} / 10^{\text {" }}$ neutrophils, + 50 $\mathrm{M} 5 \mathrm{AS} A-0.034$ nmoles $/ \mathrm{sec} / 10^{\prime \prime}$ neutrophils and $50 \mu \mathrm{M}$ sulphasalazine-0.032 nmol/sec/10" neutrophils.

inhibitory effect on the luminol dependent chemiluminescent response of neutrophils after chemotactic stimulation, which was not mirrored by similar inhibition of superoxide production or oxygen consumption.

Inhibition may result from interference at one or more sites in the chain of events which result in the production of reactive oxygen metabolites by stimulated neutrophils (Fig. 4). These include: (a) blocking of the stimulus receptor on the cell membrane, (b) direct, blanket inhibition of the cell, (c) inhibition of the oxidase system, or (d) extracellularly, by scavenging released oxygen metabolites.

Sulphasalazine and 5ASA have both been shown to inhibit the chemotactic activity of neutrophils. ${ }^{21}$ It has been suggested that these drugs inhibit neutrophil activity by blocking binding of fMLP to its receptor."2 The inhibition of luminol dependent chemiluminesence by SAL and 5ASA showed here, however, is unlikely to be a consequence of blocking the fMLP receptor, because the drugs produced little inhibition of oxygen consumption during the respiratory burst of neutrophils stimulated with fMLP+CB.

A direct non-specific effect of the drugs on the neutrophil was also excluded as there was little inhibition of PMA stimulated luminol-dependent 


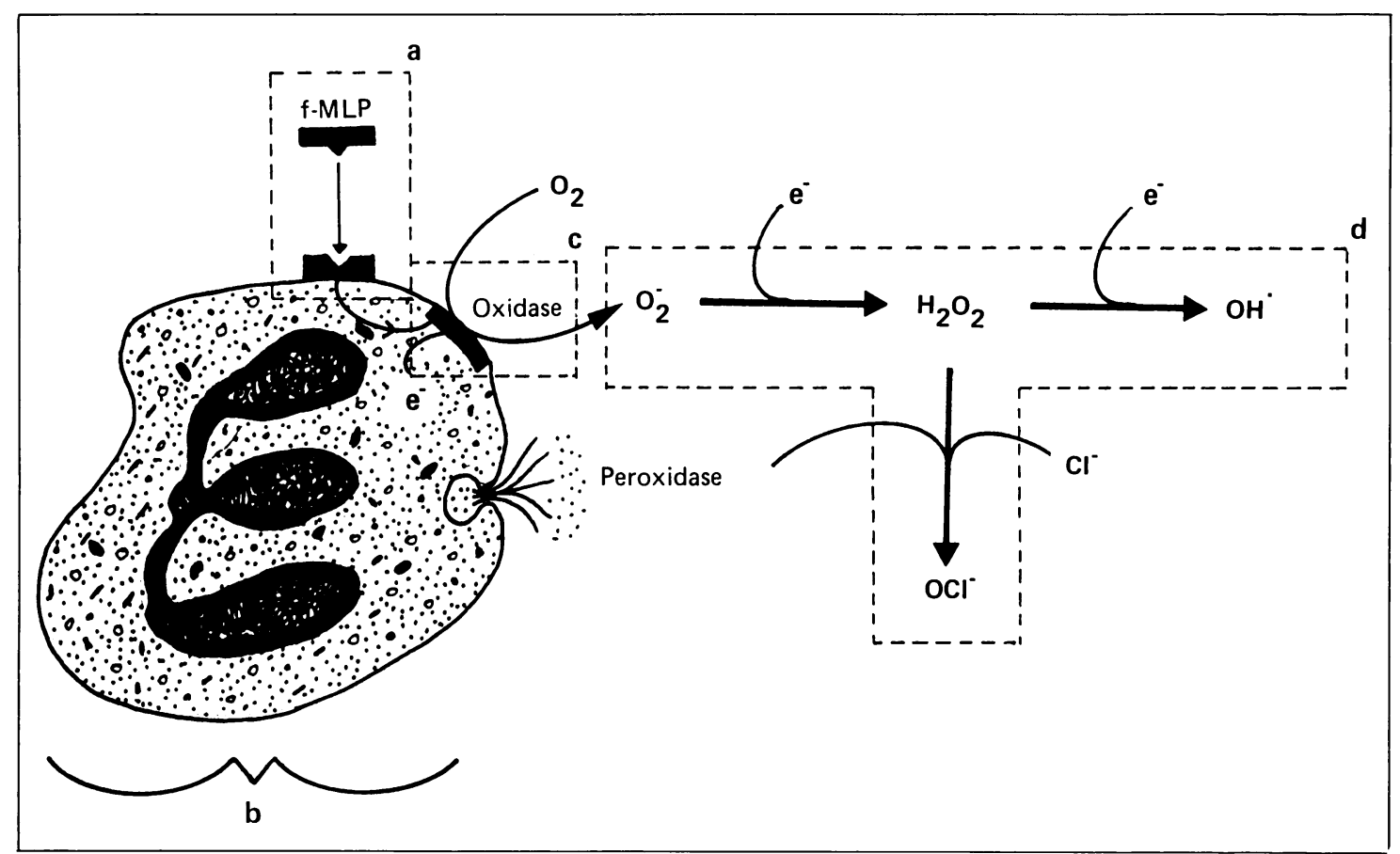

Fig. 4 Toxic oxygen metabolite production by neutrophils. Schematic representation of the mechanism of production of toxic metabolites of oxygen by stimulated neutrophils. When activated, in this situation by the chemotactic peptide $f M L P$, the oxidase system converts oxygen into superoxide $\left(\mathrm{O}^{-}{ }_{2}\right)$ by addition of an electron. Addition of further electrons results in the formation of hydrogen peroxide $\left(\mathrm{H}_{2} \mathrm{O}_{2}\right)$ and the hydroxyl radical $(\mathrm{OH})$. Myeloperoxidase, released simultaneously with oxidase activation, reacts with $\mathrm{H}_{2} \mathrm{O}_{2}$ and chloride to form hypochlorite $\left(\mathrm{OCl}^{-}\right)$. Possible sites of action of $5 \mathrm{ASA}$ and $\mathrm{SAL}$ in inhibiting luminol-dependent chemiluminesence are shown. (a) Binding of fMLP to its receptor, (b) Direct general inhibition of cellular function, (c) Inhibition of the oxidase system, (d) Extracellularly by scavenging released radicals.

chemiluminesence and oxygen consumption was not affected by sulphasalazine and 5ASA. This also excludes the possibility that the drugs acted by inhibition of the oxidase enzyme system (site c, Fig. 4).

An extracellular site of action (d, Fig. 4) therefore remains the only possibility. Previous authors have shown that sulphasalazine and its metabolites react variably with superoxide, hydrogen peroxide and hydroxyl radicals in cell-free systems. ${ }^{?-2-2 h}$ Our results suggest that superoxide is not the major metabolite being scavenged, as 5ASA only inhibited superoxide production by neutrophils by $35 \%$ and sulphasalazine by $7 \cdot 9 \%$. Luminol dependent chemiluminesence was almost totally inhibited by similar concentrations of 5ASA, which would imply that a secondary radical, formed from superoxide, is being scavenged.

Triggering of luminol dependent chemiluminesence by neutrophils depends on release of myeloperoxidase and hydrogen peroxide, conditions which generate hypochlorite. ${ }^{772}$ Sulphasalazine and 5ASA do not inhibit myeloperoxidase (unpublished obser- vations) therefore, the inhibition of luminoldependent chemiluminesence, may be the result of hypochlorite scavenging by sulphasalazine and 5ASA. Auroma et al ${ }^{5}$ showed that 5ASA scavenges hypochlorite in a cell free system and our similar conclusion, based on experiments on neutrophils, strengthens the hypothesis that 5ASA acts by scavenging hypochlorite in inflamed tissue.

Oxygen radical production by $\mathrm{fMLP}+\mathrm{CB}$ stimulated neutrophils involves exocytosis of myloperoxidase, whereas little myeloperoxidase is released after stimulation with PMA..$^{24}$ Thus hypochlorite formation occurs extracellularly after fMLP stimulation and intracellularly after PMA. The differential effect of 5ASA and SAL on luminol dependent chemiluminesence stimulated by fMLP and PMA may reflect a difference in the availability of these drugs at extracellular and intracellular sites, or differences in the generation of the peroxidasedependent metabolite.

After oral ingestion, one third of the dose of 5ASA is recovered in urine, mostly as the acetylated 
metabolite. Half the dose remains in the faeces, mostly as unchanged 5ASA. "Plasma concentration of 5ASA are low, ranging from $1.3 \mu \mathrm{M}^{311}$ to $13 \mu \mathrm{M}$, similar to the concentrations used in these experiments. Concentrations of acetyl 5ASA are roughly double this and the concentration of 5ASA in the faecal stream is much greater $(10 \mathrm{mM})$. $^{2}$ The concentration of 5ASA in the bowel wall in ulcerative colitis is unknown. A higher concentration than the plasma concentration can be postulated, however, as a result of the close proximity of the ulcerated mucosa to 'high' concentrations of 5ASA in the colonic lumen.

The work presented here, provides strong evidence that 5ASA, and to a lesser extent sulphasalazine are able to modify toxic oxygen metabolite production by neutrophils in vitro, by scavenging a luminol reactive metabolite, probably hypochlorite. Hypochlorite ions play an important part in the pathogenesis of tissue damage in inflammatory sites. As well as being a powerful oxidant, hypochlorite inactivates alpha-1proteinase inhibitor ${ }^{313}$ and also activates released neutrophil collagenase. ${ }^{\sharp 3}$ Thus, a drug which rapidly removes hypochlorite, generated by neutrophils in vivo, would ameliorate tissue damage in the acute phase, and have a prophylactic effect against the initiation of tissue damage during longterm use.

JGW was in receipt of a Wellcome Trust Research Training Fellowship in Surgery.

\section{References}

1 Svartz N. The treatment of 124 cases of ulcerative colitis with salazopyrin and attempts of stabilization in cases of hypersensitivity to sulfa. Acta Med Scand 1948; 206: 46.5-71.

2 Schroder H, Campbell DES. Absorption, metabolism and excretion of salicylsulfapyridine in man. Clin Pharmacol Ther 1972; 13: 539-51.

3 Peppercorn MA, Goldman P. Distribution studies of salicylazosulphapyridine and its metabolites. Gastroenterology 1973; 64: 240-5.

4 Azad Khan AK, Piris J, Truelove SC. An experiment to determine the active therapeutic moiety of sulphasalazine. Lancet 1977; ii: 892-5.

5 Van Hees PAM, Bakker JH, Van Tongeren JHM. Effect of sulphapyridine, 5 aminosalicylic acid and placebo in patients with idiopathic proctitis: a study to determine the active therapeutic moiety of sulphasalazine. Gut 1980; 21 : 632-5.

6 Dew MJ, Hughes PJ, Lee MS, et al. An oral preparation to release drugs in the human colon. Br J Clin Pharmacol 1982; 14: 405.

7 Morson BC, Dawson IMP. Gastrointestinal pathology. Oxford: Blackwell, 1979.

8 Babior BM. Oxygen-dependent microbial killing by phagocytes. N Engl J Med 1978; 298: 659-68.

9 Klebanoff SJ. Oxygen metabolism and the toxic properties of phagocytes. Ann Intern Med 1980; 93: $480-9$.

10) Weiss SJ. Oxygen, ischemia and inflammation. Acta Physiol Scand 1986; (suppl 548): 9-37.

11 Del Maestro RF. Thaw HH, Bjork J, et al. Free radicals as mediators of tissue injury. Acta Physiol Scand 1980; (suppl 492): 43-57.

12 Williams JG. Oxygen radical production by circulating and mucosal phagocytic cells in inflammatory bowel disease. University of Wales: M Ch thesis, 1989.

13 Williams JG. Hallett MB. The enhanced production of oxygen radicals by mucosal phagocytes in Crohn's disease. BrJ Surg 1986; 73: 1033.

14 Skoog WA, Beck WS. Studies on fibrinogen, dextran and phytohacmagglutinin methods of isolating leukocytes. Blood 1956; 11: 436-54.

15 Boyum A. Isolation of mononuclear cells and granulocytes from human blood. Scand J Clin Lab Invest 1968; 21: (Suppl 97): 77-90.

16 Allen RC, Loose LD. Phagocytic activation of a luminol-dependent chemiluminesence in rabbit alveolar and peritoncal macrophages. Biochem Biophys Res Comm 1976; 69: 245-52.

17 Campbell AK, Hallett MB, Wecks I. Chemiluminesence as an analytical tool in cell biology and medicinc. Meth Biochem Anal 1985; 31: 317-415.

18 Cohen HJ. Continuous monitoring of superoxide production by phagocytes. In: Greenwald RA, ed. CRC handbook of methods in oxygen radical research. Boca Raton: CRC Press, 1985

19 Cooke E, Hallett MB. The role of C-kinase in the physiological activation of the neutrophil oxidase. Biochem J 1985; 232: 323-7.

20 Scidell A. Solubilities of inorganic compounds. Vol 1. New York: Van Nostrand, 1940.

21 Rhodes JM, Bartholomew TC, Jewell DP. Inhibition of lcukocyte motility by drugs used in ulcerative colitis. Gut 1981; 22: 642-7.

22 Stenson WF, Mehta J. Spilberg I. Sulphasalazine inhibition of binding of $\mathrm{N}$-formyl-methionyl-leucylphenylalanine (FMLP) to its receptor on human neutrophils. Biochem Pharmacol 1984; 33: 407-12.

23 Miyachi Y, Yoshioka A. Imamura S, Niwa Y. Effect of sulphasalazine and its metabolites on the generation of reactive oxygen species. Gut 1987; 28: 190-5.

24 Dull BJ, Salata K, Van Langenhove A, Goldman P. 5-Aminosalicylate: Oxidation by activated leukocytes and protection of cultured cells from oxidative damage. Biochem Pharmacol 1987; 36: 2467-72.

25 Aruoma OI, Wasil M. Halliwell B, et al. The scavenging of oxidants by sulphasalazine and its metabolites. Biochem Pharmacol 1987; 36: 3739-42.

26 Ahnfelt-Ronne I, Nielsen $\mathrm{OH}$. The antiinflammatory moicty of sulfasalazine, 5-aminosalicylic acid, is a radical scavenger. Agents Actions 1987; 21: 191-4.

27 DeChatelet LR, Long GD, Shirley PS, et al. Mechanism of the luminol-dependent chemiluminesence of human ncutrophils. J Immunol 1982; 129: 1589-93.

28 Dahlgren C. Stendahl O. Role of myeloperoxidase in luminol-dependent chemiluminesence of polymorphonuclear leukocytes. Infect Immun 1983; 39: 736-41.

29 Hallett MB, Campbell AK. Two distinct mechanisms 
for stimulation of oxygen radical production by polymorphonuclear leukocytes. Biochem J 1983; 216: $459-65$.

30 Klotz U, Maier KE. Pharmacology and pharmacokinetics of 5-aminosalicylic acid. Dig Dis Sci 1987; 32: (suppl): 46S-50S.

31 Matheson NR. Wong PS. Travis J. Enzymatic inactivation of human alpha-1-proteinase inhibitor by neutrophil mycloperoxidase. Biochem Biophys Res Comm 1979; 88: 4()2-9.

32 Weiss SJ, Lampert MD, Test ST. Long-lived oxidants generated by human neutrophils: characterisation and bioactivity. Science 1983; 222: 625-7.

33 Weiss SJ, Peppin G, Oritz X. et al. Oxidative autoactivation of latent collagenase by human neutrophils. Science 1985; 227: 747-9. 